\title{
A Novel One-Step Knife Approach Can Reduce the Submucosal Injection Time of Endoscopic Submucosal Dissection: A Single- Blinded Randomized Multicenter Clinical Trials
}

\author{
Hyunil Kim¹, Jin Woo Kim¹, Hong Jun Park ${ }^{1,2}$, Su Young Kim¹, Hyun-Soo Kim¹, Gwang Ho Baik², Sung Chul Park', \\ Sang Jin Lee ${ }^{5}$, and Tae-Hwa Go \\ 1Department of Internal Medicine, Yonsei University Wonju College of Medicine, Wonju, ${ }^{2}$ Center of Evidence Based Medicine \\ Institute of Convergence Science, Yonsei University, Seoul, ${ }^{3}$ Department of Internal Medicine, Hallym University College of Medicine, \\ ${ }^{4}$ Department of Internal Medicine, Kangwon National University School of Medicine, Chuncheon, ${ }^{5}$ Department of Internal Medicine, \\ University of Ulsan College of Medicine, Gangneung, and ${ }^{6}$ Department of Biostatistics Center of Biomedical Data Science, Yonsei \\ University Wonju College of Medicine, Wonju, Korea
}

Article Info

Received March 7, 2021

Revised April 16, 2021

Accepted April 21, 2021

Published online June 25, 2021

\section{Corresponding Author}

Hong Jun Park

ORCID https://orcid.org/0000-0001-9320-9978

E-mail ppakongs@yonsei.ac.kr

Hyunil Kim and Jin Woo Kim contributed equally to this work as first authors.
Background/Aims: Endoscopic submucosal dissection (ESD) is a curative treatment modality for early gastric neoplasms; however, ESD can be a time-consuming process. To overcome this pitfall, we developed the one-step knife (OSK) approach, which combines an endoscopic knife and injection needle on a single sheath. We aimed to evaluate whether this approach could reduce the ESD procedure time.

Methods: This single-blinded randomized multicenter trial at four tertiary hospitals from June 2019 to June 2020 included patients aged 19 to 85 years undergoing ESD. Patients were randomly assigned to two groups (OSK or conventional knife [CK]). The injection time, total procedure time, resected specimen size, submucosal fluid amount, degree of device satisfaction, and adverse events were evaluated and compared between groups.

Results: Fifty-one patients were analyzed (OSK: 25 patients and CK: 26 patients). No baseline differences were observed between groups, with the exception of a higher portion of males in the OSK group. The mean injection time was significantly reduced in the OSK group (39.0 seconds) compared to that in the CK group $(87.5$ seconds, $p<0.001)$. A decrease of more than 10 minutes in the total procedure time ( 18.0 minutes vs 28.1 minutes, $p=0.055)$ in the OSK group compared to the CK group was observed. Second-look esophagogastroduodenoscopy revealed two delayed bleeding cases in the OSK group that were easily controlled by endoscopic hemostasis.

Conclusions: OSK reduced the injection time and showed a decrease in total procedure time compared with the CK approach. OSK can be a feasible tool for ESD, especially in difficult cases. (Gut Liver 2022;16:44-52)

Key Words: Gastric cancer; Endoscopic submucosal dissection; Submucosal injection; Procedure time

\section{INTRODUCTION}

Stomach cancer is the second most common cancer among all malignancies in Korea. ${ }^{1}$ Since 1999, the Korean National Cancer Screening Program has recommended esophagogastroduodenoscopy or upper barium radiologic testing as gastric cancer screening to the general population over the age of 40 years. As a result, over $70 \%$ of stomach cancers have been detected as early gastric cancer (EGC). ${ }^{2,3}$ Since its introduction in the early 2000s, endoscopic submucosal dissection (ESD) has provided many advantages in terms of quality of life and short- and long-term clinical outcomes. ${ }^{4-7}$ Currently, ESD has been accepted as a curative treatment modality for EGC or gastric adenoma with a steady increase in cases of up to 6,000 per year for EGC and over 23,000 per year for early gastric neoplasms. 
The ESD procedure includes marking around the lesion, submucosal injection, mucosal incision, and submucosal dissection. Among these steps, submucosal injection is an essential process that prevents perforation during mucosal incision and provides the submucosal dissection area; usually more than two submucosal injections are needed during a single ESD procedure. However, submucosal injection is a bothersome and time-consuming process that includes inevitable subprocesses such as endoscopic knife withdrawal, needle injector insertion, submucosal fluid injection, needle injector withdrawal, and endoscopic knife insertion. This process requires more than 1 minute per submucosal injection. When many subsequent submucosal injections are required, the procedural time may be substantially prolonged.

Prolonged ESD procedural time is associated with adverse events such as perforation, aspiration pneumonia, and post-ESD bleeding. ${ }^{8,9}$ Nevertheless, because some fixed parameters determine the ESD procedural time (e.g., endoscopist skill, lesion size and location, and rounds of submucosal injection), ${ }^{10-12}$ shortening the ESD procedure is not feasible using the conventional approach.

To overcome this, we developed a novel hybrid knifeinjector complex that operates similarly to using a multicolor ballpoint pen. In a preclinical animal model test, the hybrid knife-injector complex (one-step knife [OSK]; Upexmed, Anyang, Korea) showed a marked reduction of submucosal injection time.

To investigate the OSK approach in humans, we conducted a multicenter trial to evaluate whether OSK can reduce the submucosal injection time in humans and whether reducing the submucosal injection time by OSK can effectively reduce the total ESD procedure time.

\section{MATERIALS AND METHODS}

This was a single-blinded (participants) randomized multicenter trial with a parallel design including a 1:1 allocation ratio among four participating tertiary hospitals. This study was approved by the Institutional Review Board in Wonju Severance Christian Hospital (IRB number: CR218006) and was registered on clinical research information service (CRIS number: KCT0004046).

\section{Study population}

Among patients aged 19 to 85 years who had planned to undergo ESD for EGC or gastric adenoma, the patients who agreed and submitted informed consent were enrolled. We excluded patients with serious cardiopulmonary disease, coagulation disorder, and who underwent gastrectomy.
Patients were randomly assigned to either the OSK group or the conventional knife (CK) group according to a computer-generated random table with stratification of the stomach site to the body and antrum. Central allocation by telephone was used to conceal allocation.

\section{Procedures and intervention}

A total of seven endoscopists participated in this study who have experience of ESD more than 500 cases. Before the clinical trial, all endoscopists and assistants underwent an OSK operation training period using an animal model (pig stomach).

All patients underwent ESD under sedation. A standard scope (HQ290 or Q260) was used for all ESDs. After careful demarcation with white light endoscopy, indigo carmine, and narrow-band imaging, a marking around lesion was made with a knife or argon plasma coagulation.

In the OSK group, submucosal injection, mucosal incision, and submucosal dissection were performed using only an OSK. In the CK group, submucosal injection with needle injector, incision, and dissection were performed with a CK. The submucosal injection fluid was composed of $7 \mathrm{~mL}$ normal saline with $1 \mathrm{~mL}$ epinephrine $(1: 100,000)$. Injection times using a stopwatch and the amount of injection were recorded. Before finishing ESD, preventive hemostasis with hemoclips or coagrasper was done. After ESD, endoscopists and assistants filled out satisfaction questionnaires of the devices. The next day, a second-look endoscopy was performed to check for delayed bleeding.

\section{Device (OSK)}

From 2016, we developed a complex device containing a knife and needle injector comprised into one sheath. The technical development difficulties consisted of mainly three parts: (1) smooth switchover under the extremely bending situation of endoscopy; (2) simple operation handle switch to facilitate the switchover; and (3) same quality of knife tip as the CK (dual knife). After many revisions, the technical problems were resolved and we performed a clinical trial with our final product (Fig. 1).

The OSK contains two instruments (endoscopic knife and needle injector) in one channel. The endoscopic knife is identical to the dual knife (Olympus, Tokyo, Japan), which has a 2-mm knife tip. A 25-gauge needle injector of the OSK is sufficient for epinephrine mixed normal saline injection as well as hyaluronic acid mixed fluid injection. The switchover to knife or needle injector is made by a handle switch that includes a gear structure conversion mechanism (Fig. 2). An assistant can switchover between the two instruments without removing an electrode linked with the endoscopic surgical generating unit (ESU). In 


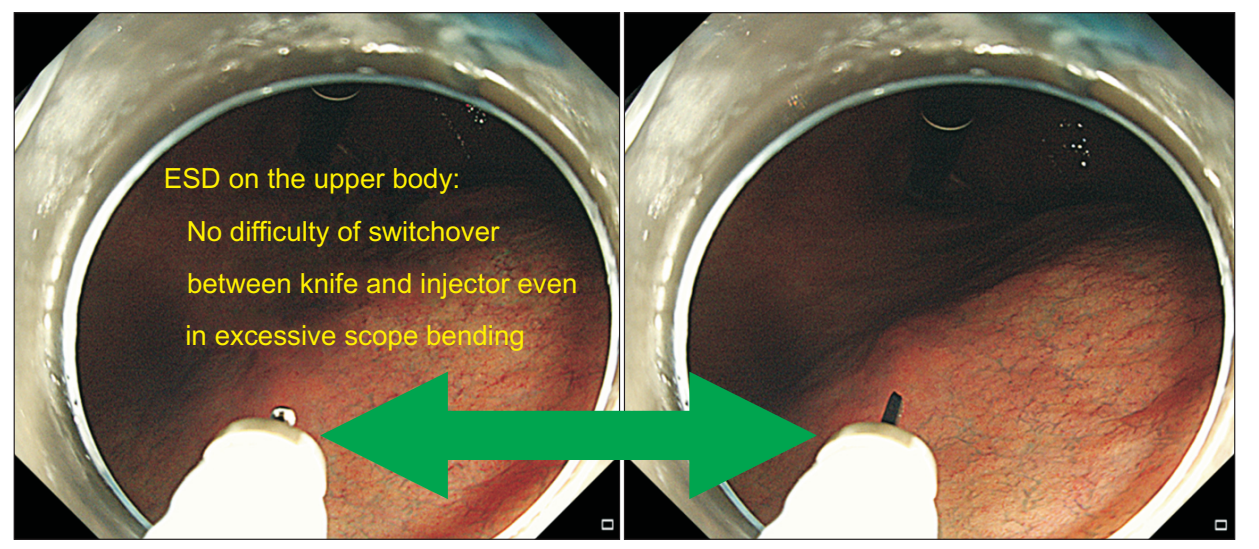

Fig. 1. Smooth switchover of one-step knife under the extreme bending situation of endoscopy. ESD, endoscopic submucosal dissection.

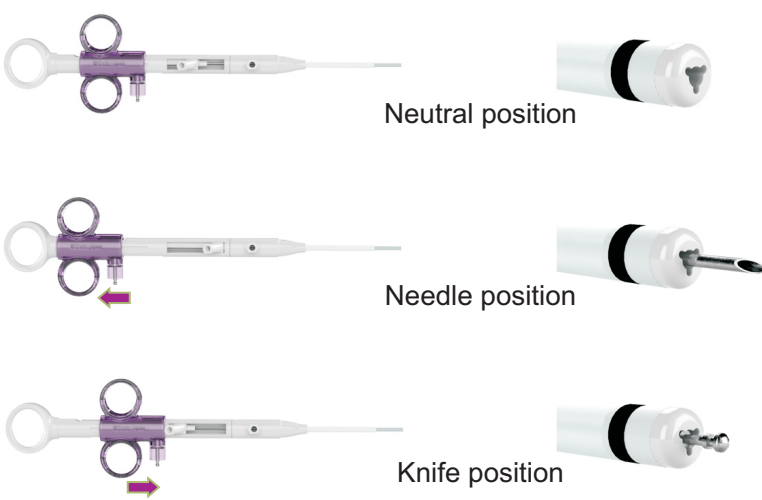

Fig. 2. The one-step knife has single channel which the endoscopic knife and needle injector pass through alternatively. The switchover between the knife and needle injector is made by a handle switch.

Korea, the dual knife or IT knife 2 are mainly used. So, we compared OSK with dual knife in point of knife efficacy. We used ESU (Erbe Vio300; Erbe Elektromedizin GmbH, Tübingen, Germany) with Endo cut Q mode.

\section{Outcomes and definitions}

The primary outcomes were injection time and total procedure time. The secondary outcomes were (1) en bloc resection; (2) resected specimen size; (3) submucosal fluid amount; (4) delayed bleeding and delayed perforation; (5) endoscopist satisfaction; and (6) assistant satisfaction.

We defined the injection time as the time from the "endoscopic knife out" for submucosal injection followed by the "endoscopic knife in" in the CK group and the time from switchover (from knife to injector) for submucosal injection followed by switchover (from injector to knife) in the OSK group. The time of the first marking to the time of falling off the specimen was defined as the total procedure time. To reduce bias, we determined the target lesion size to be $2-3 \mathrm{~cm}$ and to be without fibrosis. Stomach location could be an important factor for total procedure time; thus, we stratified the site of lesion which defined the body as the upper site and the angle to antrum as the lower site. The device satisfaction questionnaire administered to endoscopists and assistants included questions regarding overall satisfaction, overall satisfaction of the procedural process, and overall satisfaction of submucosal injection. We adopted a 5-point satisfaction scale: (1) very satisfactory, (2) satisfactory, (3) not so satisfactory, (4) dissatisfactory, and (5) very dissatisfactory.

\section{Sample size and statistical analysis}

This study was designed as a superiority test, and the independent variable was the type of knife. We defined the alpha: 0.05 , beta: 0.20 , power: 0.80 , and two tail, allocation ratio $\mathrm{N} 2 / \mathrm{N} 1$ : 1 . Based on previous animal testing in pig stomachs, we assumed the mean injection time in the OSK group to be 40 seconds, and the mean injection time in the CK group to be 60 seconds with a standard deviation of 25 seconds. The effect size(s) was 0.8 . As a result, the sample size was 22 patients per group, with a total of 44 patients in both groups. The follow-up loss rate was assumed as $20 \%$; thus, a total of 56 patients were calculated (each hospital: seven patients in the CK group, seven patients in the OSK group). We did not perform interim analysis.

Continuous data are expressed as medians with ranges or standard deviations; categorical parameters are expressed as frequencies and proportions. For continuous data, test of normality was performed using the ShapiroWilk test; non-parametric variables were compared using the Mann-Whitney $U$ test and the parametric variables were compared using the independent $\mathrm{t}$-test. Categorical parameters were compared using the chi-square test or Fisher exact test. Multiple regression for procedure time was performed after age, sex, injection number, and maximal diameter were adjusted. All p-values were two-sided and were considered statistically significant if $\mathrm{p}<0.05$. All statistical analyses were performed using SPSS software version 25.0 (IBM Corp., Armonk, NY, USA). 


\section{RESULTS}

From June 2019 to June 2020, 98 patients were screened; 42 patients were excluded for the following reasons: age $>85$ years $(n=13)$, previous gastrectomy $(n=3)$, lesions over $3 \mathrm{~cm}$ or with fibrosis $(\mathrm{n}=17)$, and declined participation $(n=9)$. A total of 56 patients were randomized to the OSK $(n=28)$ or CK $(n=28)$ groups. Among them, a total of 51 patients were ultimately analyzed except for four patients who refused the scheduled ESD (two OSK and two CK) and one patient who did not undergo the OSK approach because of an ESU error (Fig. 3).

\section{Baseline characteristics and procedural data}

Baseline characteristics were not significantly different between the OSK and CK groups, with the exception of a higher proportion of males in the OSK group than in the CK group (92.0\% vs 61.5\%, $\mathrm{p}=0.010$ ).

All patients underwent ESD under sedation. The proportions of patients receiving midazolam, propofol and pethidine were not different between the OSK and CK groups. The most common lesion morphologies were type 0 -II (IIa, IIb, IIc). No significant difference in morphology between the two groups were noted. All lesions were en bloc resected. The most common histologic diagnosis before ESD was low-grade dysplasia in both groups $(\mathrm{p}=0.090)$ (Table 1).

\section{Injection time, total procedure time}

There was a significant difference in the mean injection time between the OSK and CK groups (mean, $39.0 \mathrm{sec}$ onds; range, 26.5 to 59.5 seconds and mean, 87.5 seconds; range, 75.0 to 99.3 seconds, respectively, $\mathrm{p}<0.001)$. In addition, a reducing trend of more than 10 minutes in the OSK group compared to that in the CK group was observed in the total procedure time (mean, 18.0 minutes; range, 16.5 to 29.5 minutes and mean, 28.1 minutes; range, 18.0 to 39.6 minutes, respectively, $\mathrm{p}=0.055)$. In contrast, there were no significant differences in injection number $(\mathrm{p}=0.723)$ and maximal diameter $(\mathrm{p}=0.280)$. The total injection amounts and injection amount per one injection were significantly lower in the OSK group than in the CK group $(p=0.029$, $\mathrm{p}=0.007$, respectively) (Table 2, Fig. 4).

Multiple linear regression analysis was performed using age, sex, lesion size and knife. When examining the effect of the above variables on the procedure time, the $\mathrm{R}$ square value was 0.226 and analysis of variance was $p=0.005$. The range of variance inflation factor were 1.028 to 1.372 . The standardized coefficients betas were 0.359 on site, 0.353 on maximal diameter, and 0.269 on kind of knives, which means the procedure time is influenced by site of lesion, size of lesion and kind of knives.

\section{Subgroup analysis}

The median injection number was three per ESD; thus, we divided cases into low frequency injection (1 to 3 times) and high frequency injection (4 or more times) groups. Subgroup analysis revealed a statistically significant difference in total procedure time for the high but not the low frequency injection group ( $\mathrm{p}=0.044, \mathrm{p}=0.293$, respectively) (Table 3, Fig. 5).

\section{Satisfaction and complications}

Regarding responses to the questionnaire, endoscopists rather than assistants yielded a very satisfactory trend in device satisfaction. Endoscopists gave a statistically significant response that the OSK was very satisfactory, especially in submucosal injection ( $\mathrm{p}=0.009)$ (Table 4).

There were no perforations during the ESD procedures; however, on second-look esophagogastroduodenoscopy,

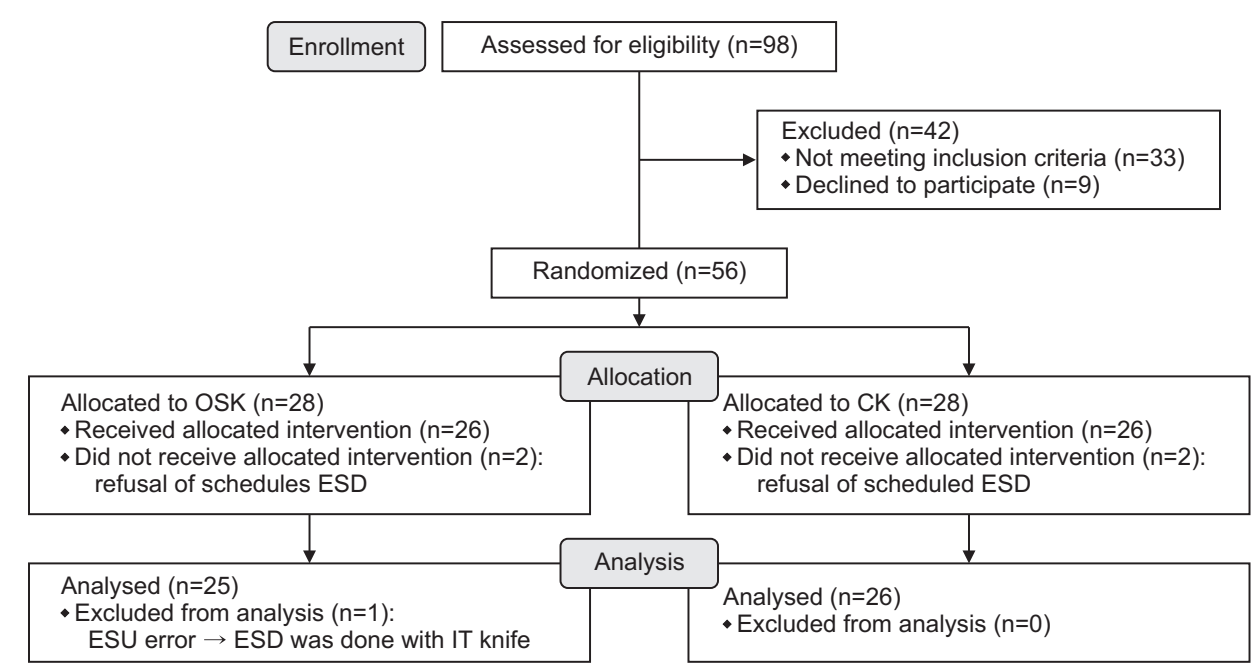

Fig. 3. Flow diagram of this study. OSK, one-step knife; CK, conventional knife; ESD, endoscopic submucosal dissection; ESU, endoscopic surgical generating unit; IT, insulationtipped. 
Table 1. Demographic and Procedure Related Data

\begin{tabular}{|c|c|c|c|}
\hline Variable & OSK (n=25) & $C K(n=26)$ & $\mathrm{p}$-value \\
\hline Age, yr & $60.0 \pm 9.1$ & $68.0 \pm 8.8$ & 0.117 \\
\hline Male sex & 23 (92.0) & 16 (61.5) & 0.010 \\
\hline \multicolumn{4}{|l|}{ Chronic diseases } \\
\hline HTN & 12 (48.0) & 11 (42.3) & 0.683 \\
\hline Diabetes & $7(28.0)$ & $6(23.1)$ & 0.687 \\
\hline Cardiologic disease & $2(8.0)$ & $3(11.5)$ & $>0.999$ \\
\hline CVA & 0 & 0 & NS \\
\hline Site (body) & $13(52.0)$ & 12 (46.2) & 0.676 \\
\hline Sedation & 25 (100) & 26 (100) & NS \\
\hline \multicolumn{4}{|l|}{ Sedatives $^{\dagger}$} \\
\hline Midazolam & $19(76.0)$ & 20 (76.9) & 0.938 \\
\hline Propofol & 14 (56.0) & 15 (57.7) & 0.903 \\
\hline Pethidine & $17(68.0)$ & 20 (76.9) & 0.475 \\
\hline \multicolumn{4}{|l|}{ Morphology ${ }^{\ddagger}$} \\
\hline Isp & $2(8.0)$ & $2(7.7)$ & $>0.999$ \\
\hline Is & $1(4.0)$ & 0 & $0.490 *$ \\
\hline Ila & $13(52.0)$ & $14(53.8)$ & 0.895 \\
\hline $\mathrm{llb}$ & $6(24.0)$ & $7(26.9)$ & 0.811 \\
\hline IIc & $8(32.0)$ & $9(34.6)$ & 0.843 \\
\hline En bloc resected & $25(100)$ & $26(100)$ & NS \\
\hline Previous diagnosis & & & $0.090^{*}$ \\
\hline LGD & $17(68.0)$ & 19 (73.1) & \\
\hline$H G D$ & $4(16.0)$ & 3 (11.5) & \\
\hline EGC & $4(16.0)$ & $4(15.4)$ & \\
\hline Final diagnosis & & & 0.331 \\
\hline LGD & $16(64.0)$ & 11 (42.3) & \\
\hline$H G D$ & $3(12.0)$ & $7(26.9)$ & \\
\hline EGC & $6(24.0)$ & $8(30.8)$ & \\
\hline \multicolumn{4}{|l|}{ EGCs" } \\
\hline Lauren (intestinal) & $5(83)$ & $7(86)$ & $>0.999$ \\
\hline Location (upper) & 2 (33) & 3 (38) & $>0.999$ \\
\hline Submucosal invasion & 0 & $1(13)$ & NS \\
\hline Mean diameter, $\mathrm{mm}$ & $9.1 \pm 2.0$ & $16.3 \pm 4.1$ & 0.002 \\
\hline
\end{tabular}

Data are presented as mean \pm SD or number (\%).

OSK, one-step knife; CK, conventional knife; HTN, hypertension; CVA, cerebrovascular accident; LGD, low-grade dysplasia; HGD, high-grade dysplasia; EGC, early gastric cancer; NS, no significance.

*Statistically significant, $p<0.05 ;{ }^{\dagger}$ Concomitant use; ${ }^{\ddagger}$ Separately described overlapping lesions (e.g., Ila + IIc); "EGCs are OSK (n=6) and CK (n=8).

Table 2. Injection Details and Maximum Diameter in Both Groups

\begin{tabular}{lccc}
\hline \multicolumn{1}{c}{ Variable } & OSK $(\mathrm{n}=25)$ & $\mathrm{CK}(\mathrm{n}=26)$ & $\mathrm{p}$-value* \\
\hline Mean injection time, sec & $39.0(26.5-59.5)$ & $87.5(75.0-99.3)$ & $<0.001$ \\
Total procedure time, min & $18.0(16.5-29.5)$ & $28.1(18.0-39.6)$ & 0.055 \\
Injection number, $\mathrm{n}$ & $3.0(2.0-6.5)$ & $3.5(3.0-5.3)$ & 0.723 \\
Total injection amount, $\mathrm{mL}$ & $41.0(20.0-54.0)$ & $47.5(36.8-78.3)$ & 0.029 \\
Amount per injection, $\mathrm{mL}$ & $10.0(6.5-13.0)$ & $12.5(10.0-18.5)$ & 0.007 \\
Maximal diameter, $\mathrm{mm}$ & $26.0(24.5-38.5)$ & $31.0(25.0-41.3)$ & 0.280 \\
\hline
\end{tabular}

Data are presented as median (interquartile range).

OSK, one-step knife; CK, conventional knife.

*Statistically significant, $p<0.05$.

we identified two cases of delayed bleeding in the OSK group, but they were easily controlled by endoscopic hemostasis.

\section{DISCUSSION}

Submucosal injection is an essential process that generates a submucosal cushion to prevent perforation during incision and creates the submucosal dissection area. ${ }^{13,14}$ 

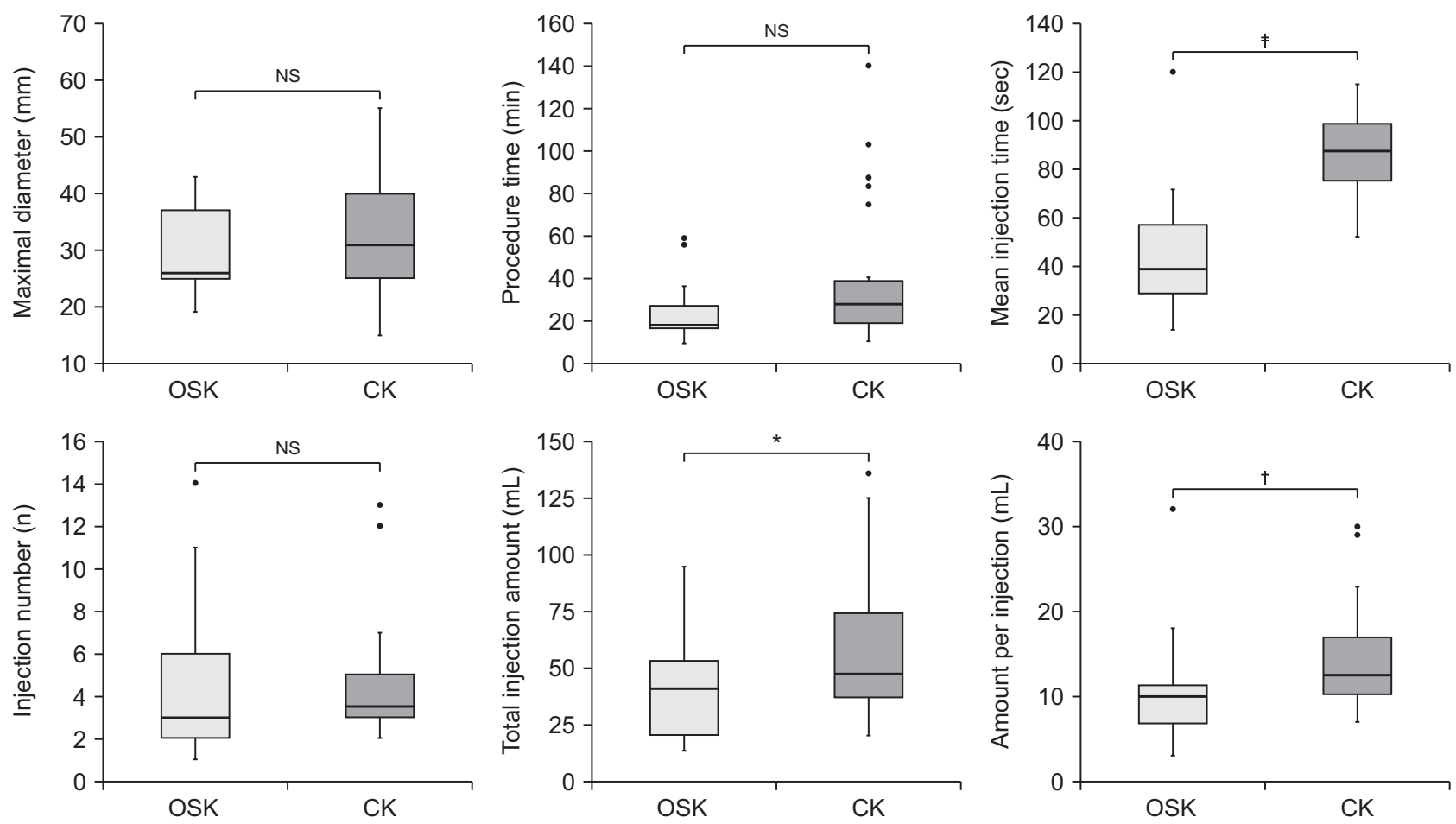

Fig. 4. Mann-Whitney $U$ test box plots of mean injection time, total injection time, injection amount, injection number, and maximal diameter in both groups.

OSK, one-step knife; CK, conventional knife; NS, no significance. ${ }^{*} p<0.05,{ }^{\dagger} p<0.01,{ }^{\ddagger} p<0.001$.

Table 3. Subgroup Analysis: Procedure Time According to Injection Number

\begin{tabular}{|c|c|c|c|c|c|c|}
\hline \multirow{2}{*}{ Variable } & \multicolumn{3}{|c|}{ Injection number 1-3 } & \multicolumn{3}{|c|}{ Injection number $\geq 4$} \\
\hline & OSK (n=13) & $C K(n=13)$ & $p$-value* & OSK (n=12) & $C K(n=13)$ & p-value* \\
\hline Mean injection time, sec & $55.0(36.0-69.5)$ & 88.0 (75.5-95.5) & 0.006 & $31.0(18.3-35.4)$ & $84.0(75.0-107.5)$ & $<0.001$ \\
\hline Total procedure time, min & $17.0(14.2-20.3)$ & $22.3(14.8-28.9)$ & 0.293 & $26.7(19.0-35.4)$ & $35.0(27.5-79.2)$ & 0.044 \\
\hline
\end{tabular}

Data are presented as median (interquartile range).

OSK, one-step knife; CK, conventional knife.

*Statistically significant, $p<0.05$.

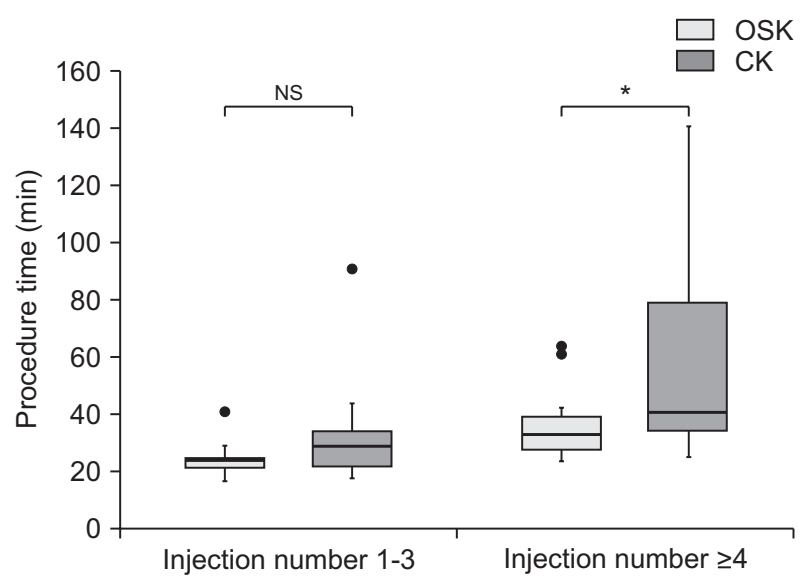

Fig. 5. Procedure time according to injection time.

OSK, one-step knife; CK, conventional knife; NS, no significance. ${ }^{*} p<0.05$.
Table 4. Results of Device Satisfaction Questionnaire

\begin{tabular}{lrcc}
\hline \multicolumn{1}{l}{ Very satisfactory } & OSK $(n=25)$ & CK $(n=26)$ & p-value* \\
\hline For endoscopists & & & \\
$\quad$ Overall & $11(44.0)$ & $5(19.2)$ & 0.057 \\
$\quad$ Procedure & $7(28.0)$ & $2(7.7)$ & 0.075 \\
$\quad$ Injection & $10(40.0)$ & $2(7.7)$ & 0.009 \\
For assistants & & & \\
$\quad$ Overall & $18(72.0)$ & $13(50.0)$ & 0.108 \\
$\quad$ Procedure & $7(28.0)$ & $9(34.6)$ & 0.611 \\
Injection & $5(20.0)$ & $4(15.4)$ & 0.726 \\
\hline
\end{tabular}

Data are presented as number (\%).

OSK, one-step knife; CK, conventional knife.

*Statistically significant, $p<0.05$.

However, the time lag between submucosal injection and incision or dissection is inevitable. The conventional approach requires a time gap to wait and observe the disap- 
pearance of the submucosal cushion. Several long-lasting solutions have been developed to overcome this timeconsuming process; however, they are expensive compared with normal saline with epinephrine mixture. ${ }^{15}$ In contrast, hybrid-type knives have been developed to have the dualfunction of both a knife and injector, such as the Flush knife (Fujinon Optical Co.), Flush knife-BT (Fujinon Optical Co.), Splash M-knife (HOYA Corp.), and HybridKnife (Erbe Elektromedizin $\mathrm{GmbH}){ }^{16-20}$ But these are not available in Korea.

It is established that the influencing factors on total procedure time are lesion size, lesion location, fibrosis, and endoscopist skill level. ${ }^{10,21,22}$ We considered these influencing factors in our trial design and controlled for the bias of the lesions by including only 2 to $3 \mathrm{~cm}$ lesions without fibrosis, lesion location via implementing an upper to lower stratification, and endoscopist skill level by including those who have experience in performing ESD on more than 500 cases.

Our results demonstrated that the OSK markedly reduced the injection time from 87 to 39 seconds and displayed a trend to reduce the total procedure time from 28 to 18 minutes. It seems that the one of reason for 10 -minute reduction in OSK group was that the lesions in standard knife groups were relatively larger. However, we think that the procedure was a little faster because the interval between using the knife after injection was short, so the procedure could be performed in a state where the submucosal fluid elevation was better maintained.

After additional analysis, there was a significant difference in the total procedure time ( $\mathrm{p}=0.044)$ in ESD procedures requiring more than four injections compared with the difference in the total procedure time $(\mathrm{p}=0.293)$ in ESD procedures requiring less than three injections. This indicated that the OSK reduced the injection time and the total procedure time in cases required more submucosal injection.

In addition, lesions that require more frequent injections would indicate that they are more difficult. When we compared the injection frequency, the upper site received injections more frequently than the lower site $(5.5 \pm 3.2$ vs $3.5 \pm 2.6$, respectively, $\mathrm{p}=0.016$ ) (data not shown). Therefore, the OSK may be more helpful in facilitating difficult ESD procedures rather than simple ESD procedures.

The adverse events were only two cases of delayed bleeding in OSK group. They were easily controlled with hemostatic clips and coagrasper. One case in the OSK group was changed from OSK to IT knife 2, where OSK function did not work and the IT knife 2 did not work either. Later, the fault was known due to ESU.
The injection amount was significantly lower in the OSK group than in the CK group. We suspect that a smaller amount was administered in the OSK group because enough cushion remained at the time of knife use since there was no time lag. But we speculate that it did not make difference of injection time because the difference of injection amount was only $2 \mathrm{~mL}$ per injection.

Compared to endoscopists who expressed a satisfactory trend with the OSK, assistants did not express a satisfactory response. We consider that endoscopists did not find much difference between the OSK and CK procedures. In contrast, for assistants, the OSK procedure could be unfamiliar because it requires maneuvering the hand switch to switchover the device.

Initially, we calculated the sample size under the hypothesis that the OSK can reduce the injection time. However, we did not consider the total procedure time as a variable to calculate the sample size. Our results showed a significant difference in the injection time but not the total procedure time. We suspect that including more patients could result in a significant difference in the total procedure time. Moreover, we did not include lesions more than $3 \mathrm{~cm}$ in size or difficult lesions (with ulcers or fibrosis) which made an insignificant difference in point of total procedure time. Further study including cases with larger sized EGCs maybe needed. In Korea, most of submucosal injection solutions are normal saline with epinephrine mixture. So, we did not compare normal saline with epinephrine mixture with hyaluronic acid solution as submucosal injection solution in OSK. In addition, hybrid knifes such as dual knife J (Olympus) are not widely used in Korea. Therefore, we compared OSK with dual knife. Hybrid knife has a multiple function such as knife and injection. To validate the efficacy of the OSK approach for difficult ESD cases, a clinical trial with more diverse lesions and compared with hybrid knife for more large population would be needed.

In conclusion the OSK approach markedly reduced the submucosal injection time from 87 to 39 seconds and resulted in a trend that reduced the total procedure time from 28 to 18 minutes. In more difficult ESD cases that require more than four submucosal injections, the OSK may be a good choice for reducing the total procedure time.

\section{CONFLICTS OF INTEREST}

No potential conflict of interest relevant to this article was reported. 


\section{ACKNOWLEDGEMENTS}

This research was supported by a grant from the Korea Health Technology R\&D Project through the Korea Health Industry Development Institute (KHIDI), funded by the Ministry of Health \& Welfare, Republic of Korea (grant number: HI19C0062).

\section{AUTHOR CONTRIBUTIONS}

Study concept and design: H.J.P. Data acquisition: H.K., H.S.K., S.Y.K., S.C.P., G.H.B., S.J.L. Data analysis and interpretation: H.K., J.W.K. Drafting of the manuscript; critical revision of the manuscript for important intellectual content: H.J.P., H.K., J.W.K. Statistical analysis: T.H.G. Obtained funding: H.J.P. Administrative, technical, or material support; study supervision: H.J.P. Approval of final manuscript: all authors.

\section{ORCID}

Hyunil Kim Jin Woo Kim Hong Jun Park Su Young Kim Hyun-Soo Kim Gwang Ho Baik Sung Chul Park Sang Jin Lee Tae-Hwa Go https://orcid.org/0000-0002-0551-6650 https://orcid.org/0000-0002-6175-6982 https://orcid.org/0000-0001-9320-9978 https://orcid.org/0000-0002-6486-8445 https://orcid.org/0000-0001-7190-0362 https://orcid.org/0000-0003-1419-7484 https://orcid.org/0000-0003-3215-6838 https://orcid.org/0000-0001-6297-7966 https://orcid.org/0000-0003-4386-0134

\section{REFERENCES}

1. Jung KW, Won YJ, Oh CM, et al. Cancer statistics in Korea: incidence, mortality, survival, and prevalence in 2014. Cancer Res Treat 2017;49:292-305.

2. Suh M, Choi KS, Lee YY, Jun JK. Trends in cancer screening rates among Korean men and women: results from the Korean National Cancer Screening Survey, 2004-2012. Cancer Res Treat 2013;45:86-94.

3. Kim YG, Kong SH, Oh SY, et al. Effects of screening on gastric cancer management: comparative analysis of the results in 2006 and in 2011. J Gastric Cancer 2014;14:129-134.

4. Kim SG, Ji SM, Lee NR, et al. Quality of life after endoscopic submucosal dissection for early gastric cancer: a prospective multicenter cohort study. Gut Liver 2017;11:87-92.

5. Choi IJ, Lee NR, Kim SG, et al. Short-term outcomes of endoscopic submucosal dissection in patients with early gastric cancer: a prospective multicenter cohort study. Gut Liver 2016;10:739-748.

6. Choi J, Kim SG, Im JP, Kim JS, Jung HC. Long-term clinical outcomes of endoscopic resection for early gastric cancer. Surg Endosc 2015;29:1223-1230.

7. Kim SG, Park CM, Lee NR, et al. Long-term clinical outcomes of endoscopic submucosal dissection in patients with early gastric cancer: a prospective multicenter cohort study. Gut Liver 2018;12:402-410.

8. Saito I, Tsuji Y, Sakaguchi Y, et al. Complications related to gastric endoscopic submucosal dissection and their managements. Clin Endosc 2014;47:398-403.

9. Nam HS, Choi CW, Kim SJ, et al. Risk factors for delayed bleeding by onset time after endoscopic submucosal dissection for gastric neoplasm. Sci Rep 2019;9:2674.

10. Lu ZS, Yang YS, Feng D, et al. Predictive factors of endoscopic submucosal dissection procedure time for gastric superficial neoplasia. World J Gastroenterol 2012;18:70097014.

11. Konuma H, Matsumoto K, Ueyama H, et al. Procedure time for gastric endoscopic submucosal dissection according to location, considering both mucosal circumferential incision and submucosal dissection. Gastroenterol Res Pract 2016;2016:9183793.

12. Nagata S, Jin YF, Tomoeda M, et al. Influential factors in procedure time of endoscopic submucosal dissection for gastric cancer with fibrotic change. Dig Endosc 2011;23:296-301.

13. ASGE Technology Committee, Hwang JH, Konda V, et al. Endoscopic mucosal resection. Gastrointest Endosc 2015;82:215-226.

14. Jung YS, Park DI. Submucosal injection solutions for endoscopic mucosal resection and endoscopic submucosal dissection of gastrointestinal neoplasms. Gastrointest Interv 2013;2:73-77.

15. Castro R, Libânio D, Pita I, Dinis-Ribeiro M. Solutions for submucosal injection: what to choose and how to do it. World J Gastroenterol 2019;25:777-788.

16. Toyonaga $\mathrm{T}$. Invention of water jet short needle knives for endoscopic submucosal dissection. Endoscopy 2005;37:A19.

17. Toyonaga T, Nishino E, Hirooka T, et al. Use of short needle knife for esophageal endoscopic submucosal dissection. Dig Endosc 2005;17:246-252.

18. Toyonaga T, Man-I M, Fujita T, et al. The performance of a novel ball-tipped Flush knife for endoscopic submucosal dissection: a case-control study. Aliment Pharmacol Ther 2010;32:908-915.

19. Esaki M, Suzuki S, Hayashi Y, et al. Splash M-knife versus Flush Knife BT in the technical outcomes of endoscopic submucosal dissection for early gastric cancer: a propensity score matching analysis. BMC Gastroenterol 2018;18:35.

20. Schumacher B, Charton JP, Nordmann T, Vieth M, Enderle 
M, Neuhaus H. Endoscopic submucosal dissection of early gastric neoplasia with a water jet-assisted knife: a Western, single-center experience. Gastrointest Endosc 2012;75:11661174.

21. Ahn JY, Choi KD, Choi JY, et al. Procedure time of endoscopic submucosal dissection according to the size and location of early gastric cancers: analysis of 916 dissections performed by 4 experts. Gastrointest Endosc 2011;73:911-916.

22. Hong KH, Shin SJ, Kim JH. Learning curve for endoscopic submucosal dissection of gastric neoplasms. Eur J Gastroenterol Hepatol 2014;26:949-954. 